\title{
UMA PERSPECTIVA IBÉRICA SOBRE A NOUVELLE GÉOGRAPHIE UNIVERSELLE DE ÉLISÉE RECLUS
}

Ricardo Coscurão

Universidade de Lisboa

\section{Resumo}

Através da presente recensão, procura-se uma abordagem da Nouvelle Géographie Universelle, da autoria do geógrafo francês Élisée Reclus, a partir da análise de uma tradução dos capítulos referentes a Portugal e à Galiza, recém-publicada por lago Bragado e Joseph Ghanime López. Trata-se de uma oportunidade para conhecer a visão deste conhecido geógrafo francês do século XIX relativamente a estes dois territórios da Península Ibérica, assim como uma ocasião renovada para analisar estes capítulos à luz de algumas das mais importantes características comuns a toda a obra de Reclus.

Palavras-chave: Élisée Reclus; Nouvelle Géographie Universelle; Galiza; Portugal; Iberismo.

\begin{abstract}
Throughout the present review, we look for an approach of the Nouvelle Géographie Universelle, authored by the French geographer Élisée Reclus, from the analysis of a translation of the chapters referring to Portugal and Galicia recently published by lago Bragado and Joseph Ghanime López. This is an opportunity to get acquainted with the vision of this well-known French geographer of the nineteenth century in relation to these two territories of the Iberian Peninsula, as well as a renewed occasion to analyze these chapters in light of some of the most important characteristics common to the entire work of Reclus.
\end{abstract}

Key words: Élisée Reclus; Nouvelle Géographie Universelle; Galicia; Portugal; Iberianism.

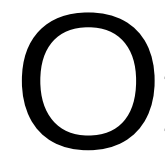

percurso e obra de Jacques Élisée Reclus (1830-1905), prestigiado geógrafo e anarquista francês, têm sido frequentemente abordados, existindo inúmeros trabalhos neste sentido. Ferretti (2011) faz referência a uma "redescoberta" da obra de Reclus, algo que, de acordo com o mesmo autor, teve início nas décadas de 1970 e 1980, particularmente através do trabalho de revistas como Antipode e Hérodote. Ferretti (2011) considera ainda que as releituras da obra de Reclus continuam atualmente, preocupando-se, sobretudo em combater eventuais anacronismos e leituras parciais.

É neste contexto que deve ser enquadrada a publicação de uma tradução dos textos relativos aos territórios da Galiza e de Portugal, presentes na Nouvelle Géographie Universelle (19 vols., 1876-1894) de Élisée Reclus, que acaba de ser proposta pela Através-Editora. Tal como referem lago Bragado e Joseph Ghanime López, os autores da tradução, "pretendeu-se com esta escolma divulgar a obra do geógrafo anarquista junto do público leitor em língua galega ou portuguesa" (p. 21).

Esta tradução contempla um prólogo assinado pelo historiador galego Eliseo Fernández. 
Reconhecido especialista em temas anarquistas, num texto intitulado "Élisée Reclus, anarquista e geógrafo", Fernández faz uma apresentação do percurso de Reclus, salientando, entre outros aspetos, a sua orientação ideológica, os movimentos em que participou e as principais obras que desenvolveu. Ao escrever o seu texto, Eliseo Fernández sublinha a atualidade do pensamento de Reclus, referindo que "a linguagem singela e formosa, o espírito rebelde e combativo ultrapassam o seu tempo e alcançam o nosso, sobrevivem com frescura mais de um século após a morte do seu próprio autor" (p. 19).

Na sua nota introdutória a esta tradução parcial da Nouvelle Géographie Universelle, lago Bragado e Joseph Ghanime López localizam os textos selecionados e traduzidos da obra original de Reclus, sendo que as partes relativas a Portugal correspondem ao capítulo XI do volume I e os textos relativos a Santander, Astúrias e Galiza correspondem à epígrafe VII do capítulo X da Nouvelle Géographie Universelle. Como base para a elaboração desta tradução, foi utilizada a edição original da obra, publicada em 1876 pela Libraire Hachette. Nesta nota introdutória são, ainda, apresentados alguns aspetos formais, nomeadamente quanto a alguns vocábulos utilizados, toponímia e tecnicismos.

Feitas as apresentações a esta tradução, os leitores têm oportunidade de conhecer um pouco da Nouvelle Géographie Universelle de Élisée Reclus, tendo contacto, em primeiro lugar, com um capítulo intitulado "Santander, Astúrias e Galiza", em que estes territórios são minuciosamente descritos. Reclus começa por apresentar os aspetos relativos ao relevo, seguindo-se uma caracterização do clima e da respetiva rede hidrográfica. Após esta descrição voltada para os elementos físicos da paisagem, o autor dedica-se a aspetos relacionados com a Geografia Humana. Nestas descrições, Reclus refere-se às aglomerações populacionais, às vias de comunicação, aos principais portos, bem como às origens das populações locais e aos seus dialetos. Subjacentes às suas descrições vão estando presentes alguns aspetos de natureza histórica, através dos quais vai contextualizando as mesmas descrições. O âmbito mais urbano não é esquecido por Reclus, descrevendo algumas cidades, nomeadamente Lugo, Ourense e Tui. Para Reclus, nestas regiões "há muitos lugares cheios de encanto" (p. 46).

Apresentado o território galego, é a vez de Portugal, estando a sua descrição dividida em seis capítulos: "Visão global"; "Portugal do norte, vales do Minho, do Douro, do Mondego"; "O vale do Tejo, Estremadura"; "O sul de Portugal: o Alentejo e o Algarve"; "Presente e futuro de Portugal" e "Governo e administração". Como o próprio título indica em "Visão global", Reclus apresenta alguns traços gerais com vista à caracterização do território português, nomeadamente quanto às respetivas características físicas, bem como às características da população.

Esta visão geral dá lugar a um percurso pelo território de Portugal continental, iniciado pelo capítulo "Portugal do norte, vales do Minho, do Douro, do Mondego". Reclus segue a mesma estrutura adotada na descrição do território galego, abordando, em primeiro lugar, as questões relativas ao relevo, ao clima e aos rios, voltando-se, em seguida, para a população e as atividades económicas - com especial destaque para o vinho do Porto, a criação de gado e, ainda, o cultivo de frutas e legumes. O autor não esquece, mais uma vez, as questões urbanas e de povoamento, fazendo referência a várias vilas e cidades do norte e do centro de Portugal, como, por exemplo, Porto, Gaia, Espinho, Ponte de Lima, Braga, Guimarães, Bragança, Coimbra, Figueira da Foz, Aveiro, entre muitas outras. 
Segue-se "O vale do Tejo, Estremadura", páginas em que Reclus começa por destacar a importância do Tejo, rio que estrutura a própria descrição deste território, proposta por Reclus. O autor refere, por exemplo, que "o curso inferior do Tejo divide Portugal em duas metades desiguais, muito diferentes pelo aspeto geral e pelos contrastes do solo e do clima" (p. 89). Apesar de fazer referência a várias localidades nesta região, Reclus dedica uma parte substancial deste capítulo à cidade de Lisboa, caracterizando-a e apresentando um pouco da sua história, com destaque para os sucessos associados ao terramoto de 1755. A "importância natural de Lisboa, porém, não só se deve à sua posição com respeito ao resto de Portugal, mas também, e, sobretudo, à situação que ocupa relativamente à Europa e ao mundo" (p. 98), acrescenta Reclus, numa das frases em que justifica, de forma clara, o aprofundamento da análise relativa à capital portuguesa.

De Lisboa e do vale do Tejo, Reclus partiu para a descrição do sul de Portugal, tratando conjuntamente as regiões do Alentejo e do Algarve. Para estes casos, manteve a estrutura adotada nas descrições anteriores, começando por se dedicar aos aspetos físicos, nomeadamente quanto ao relevo e à vegetação, referindo-se, em seguida, à população. Observa-se que o Alentejo é a parcela de Portugal que descreve com menos entusiasmo, referindo mesmo que "esta região, que vai do Tejo até às montanhas do Algarve, é a menos bela de Portugal” (p. 113).

No capítulo "Presente e futuro de Portugal", Reclus apresenta um pouco da história de Portugal, sobretudo do período dos descobrimentos e da expansão ultramarina, desencadeados nos séculos XV e XVI. Transparece que o autor manifesta, aqui, uma preocupação especial em transmitir a ideia de que os resultados das investidas colonizadoras, por parte de Portugal, não foram duradouros. Reclus refere, por exemplo, que "a colossal tarefa de conquista e colonização que os portugueses atribuíram a si próprios era grande demais para um povo tão pequeno e sem liberdade" (p. 124). Em contrapartida, Reclus não deixa de realçar progressos, entretanto realizados, referindo, por exemplo, que "o país já conta com uma rede de caminhos-de-ferro cujas rotas principais estarão concluídas em poucos anos" (p. 128). Dando voz a um projeto político de cunho iberista, o geógrafo francês entende que o futuro de Portugal deveria passar por relações cada vez mais estreitas com Espanha, pois "não há dúvida de que a similitude na vida social e industrial acabará por prevalecer, trazendo com ela a federação política" (p. 132).

No último capítulo contemplado nesta tradução, "Governo e administração", Reclus descreve a organização das instituições do governo e da Igreja, o exército, as finanças e, ainda, as distintas unidades administrativas do país.

Através desta tradução, lago Bragado e Joseph Ghanime López oferecem ao leitor a possibilidade de contactar com uma das mais emblemáticas obras de Élisée Reclus. É certo que se trata apenas de uma pequena parcela da Nouvelle Géographie Universelle. No entanto, não deixam de estarem patentes vários aspetos comuns a toda a obra e sintomáticos da qualidade literária de Reclus. Neste sentido, os tradutores desta edição souberam conservar o estilo claro e simples das descrições de Reclus, que os especialistas referem por norma (GIBLIN, 1998), sendo que, sem deixar de fornecer descrições suficientemente completas e pertinentes, a leitura desta tradução é sempre aprazível e fluída.

$\mathrm{Na}$ tradução em análise conservaram-se, também, vários mapas e figuras que integravam a edição original da obra, algumas das quais de particular qualidade estética, como é o caso da vista da cidade de Lisboa (p. 99). A inclusão destes elementos gráficos constitui um elemento que 
valoriza de sobremaneira a presente edição.

Pelletier (2009), um dos autores que mais se tem dedicado ao estudo do percurso de Élisée Reclus, reconhece que o posicionamento claramente anarquista de Reclus não é evidenciado na Nouvelle Géographie Universelle. Porém, não deixa de notar uma certa crítica ao poder instituído, ainda que de uma forma implícita. No caso da tradução em análise, este aspeto pode ser particularmente identificado no capítulo "Presente e futuro de Portugal", onde, como já foi referido, Reclus destaca os resultados menos positivos do passado de um Portugal colonizador. A propósito da rivalidade entre portugueses e espanhóis, Reclus refere ainda que a mesma "é habitual entre populações limítrofes regidas por leis diferentes, e com frequência armadas umas contra as outras por capricho dos seus soberanos" (p. 56), acrescentando que, por isso mesmo, "a maioria dos portugueses e dos espanhóis detestam-se e olham-se com receio" (p. 56).

Uma das particularidades da obra de Reclus, também referida por autores como Pelletier (2009), diz respeito à relação entre espaço e tempo, aspeto que reencontramos nesta tradução, desde logo quando observamos como as descrições das várias regiões são sempre acompanhadas de um certo enquadramento histórico. De referir, ainda, a atenção dada por Reclus ao fenómeno urbano, evidência igualmente destacada por Pelletier (2009) como uma das imagens de marca da sua obra e que também podemos identificar nas múltiplas referências e descrições das principais cidades de Portugal e da Galiza, integradas nesta edição.

Não será certamente um fruto do acaso que esta tradução tenha acabado por reunir, num mesmo livro, uma série de textos relativos à Galiza e a Portugal. Trata-se, como já foi referido, de uma publicação da Através-Editora, etiqueta editorial de âmbito galaico-português associada à Associaçom Galega da Língua (AGAL). Publicando, conjuntamente, a tradução dos textos relativos ao território galego e ao território português, selecionados da obra de Reclus, os pontos em comum entre estes dois territórios podem, assim, sair reforçados. Além disto, o próprio texto de Reclus contempla algumas passagens onde esta ideia das relações entre Portugal e Espanha está patente. Tal como já foi referido, no capítulo "Presente e futuro de Portugal" Reclus defende o estreitamento de relações entre portugueses e espanhóis, chegando a falar em "federação política" (p. 132) e a referir que os portugueses são "iguais aos espanhóis pelo seu passado grandioso e pelo papel desempenhado durante o período épico do começo da História Moderna" (p. 132), razão pela qual "também se equiparam aos seus vizinhos nas suas qualidades morais" (p. 132).

Esta tradução constitui, assim, uma oportunidade para o leitor de língua portuguesa conhecer um pouco mais sobre Jacques Élisée Reclus e a sua Nouvelle Géographie Universelle e oferece-nos um dos mais recentes exemplos do interesse sentido pelo percurso e obra deste célebre geógrafo oitocentista. Ao mesmo tempo, exemplifica uma seleção criteriosa de conteúdos, que não esconde um propósito de sentido político, que alguns sectores intelectuais galegos projetam para a atualidade peninsular. 
Referências

PELLETIER, P. Élisée Reclus, géographie et anarchie. Paris: Les Éditions du Monde Libertaire, 2009.

GIBLIN, B. Présentation. In: Élisée Reclus. L’homme et la Terre. Paris: La Découverte, 1998, p. 5-99.

FERRETTI, F. Reclus, géographie et anarchie (Philippe Pelletier). Les Cafés Géographiques, jan. 2011. Secção Des livres. Disponível em: <http://cafe-geo.net/wp-content/uploads/elisee-reclus_phpelletier.pdf>. Acesso em: 5 fev. 2017 